\title{
Othering of Full-Time and Volunteer Women Firefighters in the Canadian Fire Services
}

\author{
Lynne Gouliquer \\ Laurentian University, Canada
}

\section{Carmen Poulin}

University of New Brunswick, Canada

Jennifer McWilliams

University of New Brunswick, Canada

DOI: http://dx.doi.org/10.18778/1733-8077.16.3.04

\section{Keywords:}

Othering;

Marginalization;

Women Firefighters;

Canada; Psycho-Social

Ethnography of the

Commonplace (P-SEC)

\begin{abstract}
Being discriminated against because of factors such as gender, ethnicity, age, sexual orientation, and stature (i.e., height and weight) has been a common experience for women in traditionally men-dominated/identified occupations. Although women's representation has risen in other men-dominated domains (Hughes 1995), within firefighting their presence remains extremely low in Canada (4.4\% [Statistics Canada 2017]). Women firefighters mostly operate in a patriarchal context; they are often ignored, harassed, and treated poorly due to an intersectionality of factors (Paechter 1998). Thus far, most research has taken place in the US, UK, and AUS. In the present Pan-Canadian study, we examined the experiences of volunteer and career women firefighters ( $\mathrm{N}=113)$. The Psycho-Social Ethnography of the Commonplace methodology (P-SEC [Gouliquer and Poulin 2005]) was used. With this approach, we identified several practices, both formal and informal (e.g., physical and academic standards, gender roles), which resulted in women feeling the effect of the intersection of gender and firefighting. Results indicated that women firefighters experience "Othering" manifesting itself in a variety of ways such as discrimination, hostility, and self-doubt. This paper focuses on Canadian women firefighters and ends with social change and policy recommendations to better their reality.
\end{abstract}

Lynne Gouliquer is a Professor of Sociology at Laurentian University (ON, Canada) and an Honorary Research Associate at the University of New Brunswick (NB, Canada). Her research focuses on the sociology of organizations and marginalization theory as it applies to particular groups such as women in non-traditional work, older adults living in place, and Métis. She received her PhD from McGill University. As a former Banting Postdoctoral Fellow, she was the principal investigator on a project that examined the experience of ageing-in-place amongst individuals $90+$ years old 
and is presently documenting the experience of the Eastern Métis people.

email address: lgouliquer@laurentian.ca

\section{Carmen Poulin is an Associate Dean of Arts and a Profes-} sor of Psychology, Gender \& Women's Studies at the University of New Brunswick, Canada. Her main research interests focus on the psychological impact of social practices, the daily lives of women and marginalized groups, feminist epistemologies, and the history of women in Psychology. With Lynne Gouliquer, she developed the Psycho-Social Ethnography of the Commonplace (P-SEC) methodology, which has been successfully used to investigate the reality of various marginalized groups (e.g., mothers of autistic children, LGBT soldiers and their partners, Indigenous women).

email address: carmen@unb.ca
Jennifer McWilliams is a PhD Candidate in the Department of Psychology at the University of New Brunswick. Her research interests include the psycho-social impact of social and cultural practices on the daily lives of marginalized populations and women in men-dominated occupations, as well as the effects of stereotyping, prejudice, and discrimination on Black women and men. During her Social Sciences and Humanities Research Council (SSHRC)-funded Master's project, she examined the experiences of ageing career women firefighters in Canada. Her PhD thesis, which is supported by both SSHRC and the O'Brien Foundation, focuses on the lived experiences of sibling caregivers of individuals with intellectual disabilities who reside in Ontario and New Brunswick.

email address: jsanfor1@unb.ca

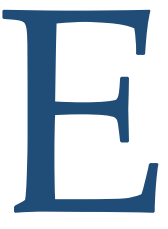
fforts to recruit women into non-traditional occupations (e.g., firefighting, policing, military) have increased in recent years (Hughes 1995; Batty and Burchielli 2011). Overall, however, progress has been minimal in remedying the deficit of women in many fields of work (Judd and Oswald 1997; Hulett et al. 2008a; Wright 2008; Gouliquer 2011; Jahnke et al. 2012). This is the case with firefighting globally, as women struggle with multiple barriers (e.g., discrimination, harassment, poor equipment, archaic promotion systems) (e.g., AUS: Beatson and McLennan 2005; McLennan and Birch 2006; Batty and Burchielli 2011; CA: Poulin, Gouliquer, and Moore 2018; US: Yoder and Aniakudo 1996; Wang and Kleiner 2001; Hulett et al. 2008b). In North America, women constitute $7.3 \%$ of the United States (Haynes and Stein 2016) and $4.4 \%$ of Canadian firefighters (Poulin et al. 2018; Statistics Canada 2017). The underrepresentation of women in firefighting is not surprising, given the domination by men surrounding labor-intensive and uniformed occupations (e.g., law enforcement, transportation, construction, military [Martin 1990; Gouliquer 2011; Wright 2016]). Moreover, women of ethnic minorities (e.g., African, Aboriginal, Hispanic), older women, and non-heterosexuals (e.g., lesbian, gay, bisexual)-who comprise 3.5\% (lesbian), $1.9 \%$ (gay), and 2.1\% (bisexual) in the general population of the US, Canada, and the UK (Gates 2011) are further underrepresented.

Multiple factors have impeded women's integration into firefighting and other non-traditional occupations (e.g., Wang and Kleiner 2001; Yoder and Aniakudo 2001; Batty and Burchielli 2011; Gouliquer 2011; Sinden et al. 2013; Poulin et al. 2018). Factors such as race and sexual discrimination and harassment have negatively contributed to women's overall acceptance and inclusion from the profession of firefighting (Yoder and Aniakudo 
1996; 1997; Yoder and Berendsen 2001). The identification of firefighting as physically and mentally draining has been presented as hampering women's integration (Flynn 2000). While some studies have been conducted in other Western countries, little research exists pertaining to Canadian women firefighters (except for Sheppard 2001; Klassen and Gillin 2005; and our recent book chapter [Poulin et al. 2018]). The present research is in response to this gap in the literature.

Women commonly experience a process of exclusion in men-dominated occupations and organizations as they are often perceived as different from the stereotype of the ideal worker (Acker 1990). According to Lewis (1997) and Rapoport and colleagues (2002), the "ideal worker" for most men-dominated employment is a man whose ability to work is not hindered by social, emotional, and caretaking obligations outside of work. This stereotype is underpinned by such masculine-associated attributes as strength, competitiveness, decisiveness, and instrumentality; while caretaking and social networking are stereotypically perceived as feminine, and women's work (Lewis 1997; Rapoport et al. 2002). Thus, it is presumed that only masculine traits are necessary to be successful in men-dominated fields and that men are not burdened with other life demands (Bleijenbergh, van Engen, and Vinkenburg 2011). In general, women and men who do not conform to masculine characteristics and the masculine hegemony are made invisible and excluded through a process called Othering (Rapoport et al. 2002; Bailyn 2006; Bendl 2008).

\section{Othering}

According to Staszak (2008:2), Othering is "a discursive process by which a dominant in-group ('Us,' the
Self) constructs one or many dominated out-groups ('Them,' Other) by stigmatizing difference-real or imagined-presented as a negation of identity and thus a motive for potential discrimination." More simply, Othering is a process that uses exclusionary criteria based on undesirable characteristics between two or more groups (Broome 2012) to discriminate. The "negation" of identity is what separates the marginalized group from the dominant group (Pettigrew and Meertens 1995; Riach 2007; Staszak 2008). Hence, the process of Othering is grounded in the application of overly simplistic stigmatizing stereotypes (Riggins 1997; Lister 2004; Staszak 2008; Jensen 2011). Othering can be violent (e.g., xenophobia, genocide, rape) or non-violent (e.g., isolation, exclusion of ethnic or religious minorities), but it is often the non-violent acts that are more harmful to marginalized individuals (Hudson and Melber 2014) as they have insidious, long-term psychological effects. Non-heterosexual and non-traditionally gendered people, ethnic and religious minorities, and immigrants are groups typically targeted in both violent and non-violent acts (Hudson and Melber 2014).

Otherness, which can occur either geographically (e.g., Western vs. Eastern cultures) or spatially (e.g., segregation to ghettos, insane asylums), works to prevent intermixing between two or more groups (Staszak 2008). Otherness and identity are constructed using opposing binary categories such as man/woman, heterosexual/homosexual, or ingroup/out-group (Paechter 1998; Bannerji 2000; Gingrich 2004; Staszak 2008; Jensen 2011; Paragg 2015). The construction and experiences of Otherness are underpinned by an asymmetry in power (Said 1978; Paechter 1998; Staszak 2008) and the exclusion of the out-group from sites of power and meaning-making (Weiner 1994). In general, dominant in-groups are the individuals who create the rules and im- 
pose identities and worldviews on the out-groups (Staszak 2008; Hudson and Melber 2014), believe and behave as if they are the only ones who matter (Paechter 1998), and are in a powerful position that can be used to devalue and inflict discriminatory measures upon the Others (Staszak 2008). The outgroup is oppressed, Othered, and subjected to the rules and practices of the in-group: they do not have the power to change the rules (Staszak 2008).

Reality is a rich mix of complex, conflicting, and intersecting identities that are not conductive to the binary nature of Otherness (Paechter 1998). An African American lesbian may prioritise her gender, race, or sexual orientation to resist her Otherness in certain situations, but may be treated differently by individuals who are also Othered (e.g., white women) due to the intersectionality of these factors (Carby 1997; Paechter 1998; hooks 2000). Overall, Othering is a social tool used to marginalize a group and disqualify their membership into the dominant ingroup (Tsouroufli, Ozbilgin, and Smith 2011). This paper investigates Othering of women in the Canadian fire services.

\section{The Fire Services' Masculinized Environment}

Fire services are para-military institutions (Hulett et al. 2008b; Poulin et al. 2018) - with an attachment to heterosexualism (Ainsworth, Batty, and Burchielli 2014) and masculinized heroism (Greenberg 1998) - and shares commonalities with other "total institutions," such as militaries (Goffman 1960). Firefighters are segregated from family, friends, and society through the use of mandatory uniforms and communal-style workplaces (Craig and Jacobs 1985; Hulett et al. 2008b). Within this seemingly "united" atmosphere, strong bonds are often formed between men, especially White men, while non-White men and women of all races, ages, sizes, and sexual orientations are Othered (Yoder and Berendsen 2001). According to Batty and Burchielli (2011), a masculinized language and culture are symptomatic of fire services and function to marginalize and alienate women. When women enter men-dominated occupations, they are often met with heightened, elaborate performances of masculinity in conjunction with the denial of feminine-associated characteristics and culture (e.g., teasing and devaluing motions) that are both threatening and demeaning to women (Batty and Burchielli 2011; Ainsworth et al. 2014). These performances, which are fueled by negative stereotypes about and attitudes towards women, are utilized as deterrents to both current and prospective women workers to disempower them (Batty and Burchielli 2011; Ainsworth et al. 2014Ainsworth). For example, women are frequently subjected to negative slurs such as "bitch," "whore," or "troublemaker" (Yoder and Aniakudo 1996).

The use of degrading language is intensified through the creation of an inhospitable and harassing working environment (Yoder and Aniakudo 1996; Batty and Burchielli 2011). Women are given ill-fitting gear, their privacy is violated, and pranks, teasing, and hazing behaviors exceed those experienced by their men coworkers (Yoder and Aniakudo 1996; Batty and Burchielli 2011; Poulin et al. 2018). Insufficient job instruction, excessive and punitive supervision, and gender/sexual harassment (Wright 2011; Ainsworth et al. 2014; Poulin et al. 2018) are additional barriers that women face. Research indicates that women firefighters are excluded from day-today interactions (Yoder and Berendsen 2001), given the "silent treatment" (Yoder and Aniakudo 1997) or left behind at the fire station during emergency calls (Yoder and Aniakudo 2001). Across multiple 
studies (e.g., Yoder and Aniakudo 1996; 2001; Yoder and Berendsen 2001; Sinden et al. 2013; Ainsworth et al. 2014; Poulin et al. 2018), women reported feeling purposefully ignored by their men counterparts, having had to hide weaknesses, and not being able to seek help without scrutiny. Feelings of isolation due to a lack of other women coworkers or segregations of women within the firefighting environment were common (Yoder and Berendsen 2001), as was the ongoing need to prove themselves to their men colleagues (Yoder and Aniakudo 1997; Yoder and Berendsen 2001; Poulin et al. 2018).

What has been minimally researched is the intersection of the different out-group identities related to gender, race, sexual orientation, age, and stature, and the discriminatory practices that have come about due to these intersectionalities.

\section{Discrimination Based on Multiple Differences}

Women firefighters have always been treated poorly based on their gender (Craig and Jacobs 1985). For women minorities, however, discrimination is complicated by the intersection of other statuses. In a study by Yoder and Aniakudo (1996), African American women reported race-based differential treatment as well as being treated differently based on gender. While most of these women (82\%) agreed that racial discrimination was an issue, a smaller number $(50 \%)$ identified sex discrimination as a problem. Sexual harassment has been a central theme in most studies about women firefighters (Yoder and Aniakudo 1996; 1997; Shuster 2000; Yoder and Berendsen 2001; Ainsworth et al. 2014; Poulin et al. 2018). However, when gender intersects with sexuality, race, or non-traditional gender, sexual harassment becomes ambiguous as to whether it is linked to gender, race, sexual orientation, or a combination (Wright 2008).

\section{Implications of Discrimination and Harassment Based on Othering}

Discrimination and harassment based on Othering dominate many men-dominated fields, and have serious emotional and physical consequences for women. They have been linked also to distrust in the system (Batty and Burchielli 2011), job dissatisfaction (Sinden et al. 2013), early retirement or job departure due to interpersonal conflict with men-colleagues, lack of promotion opportunities (Griffith et al. 2015), and lower participation in the fire services' events (Batty and Burchielli 2011). Despite these negative occurrences, women firefighters have prevailed, albeit in small numbers in the fire services.

\section{Purpose of Present Study}

Although some progress that has been made during the past few decades in the workplace, women firefighters still struggle to feel like they are a part of the dominant in-group (i.e., white heterosexual men). As outlined in the literature above, women have been excluded, harassed, discriminated against, treated differently, subjected to jokes, teased, and subjected to hazing behaviors due to multiple factors (e.g., gender, ethnicity/race, age). Moreover, factors such as pregnancy, parenthood, menstruation, height, weight, physical strength have created create additional barriers for women. Additionally, traits or characteristics that are not indicative of the men stereotype firefighter (e.g., heroic, brave, strong, masculine) are threatening and subsequently Othered. As evidenced in the literature, there is a need to explore the experiences and realities of women engaged in 
full-time and volunteer firefighting in Canada as they are the "outsiders within" (i.e., a part of the ingroup and out-group) and can provide a unique perspective on events (Yoder and Aniakudo 1997). Due to Canada's expansive territory, it is very rural in nature; thus most fire services are largely comprised of volunteers. This factor has rarely been a factor to be considered in previous studies. Yet, it deserves attention. This paper focuses specifically on Canadian women firefighters' experiences of Othering and its intersectionality with other differences such as age or a racialized identity.

\section{Methodology: The Psycho-Social Ethnography of the Commonplace}

In the present research, we utilized the Psycho-Social Ethnography of the Commonplace (P-SEC [Gouliquer and Poulin2005]) methodology. P-SEC is an interdisciplinary methodology that is inspired by three traditions (Poulin and Gouliquer 2012): 1) feminist standpoint epistemology (Harding 1987), 2) institutional ethnography (Smith 1987), and 3) schema theory (Bem 1983; 1993; Beals 1998).

Traditionally, firefighting was comprised of only men; thus, the practices, culture, and policies developed without women, which further marginalizes them. Due to its nature, relations of ruling manipulate and control human behavior (Smith 1987; 2005). Marginalized groups reify their marginalization by taking part in the ideological and material relations of ruling; therefore, marginalized individuals often behave in ways that maintain the hegemony. P-SEC uses institutional ethnography to problematize the disparities between the individual experience and the social relations of ruling embedded in organizations (Smith 2005). More specifically, P-SEC directs researchers to examine ordinary everyday events, practices, or policies of the institution that complicate the lives of the marginalized group, which are known as "Organizational Moments." Thus, the marginalized reality, as shaped by the Organizational Moment, helps illuminate how the relations of ruling operate (Poulin and Gouliquer 2012).

Concepts from schema theory were integrated into the P-SEC methodology to illustrate how marginalized individuals make sense of their institutional reality and the complications they experience. Making sense, according to schema theory, requires creating, storing, and applying cognitive concepts (e.g., stereotypes) that allow individuals to easily process information (Bransford and Johnston 1972; Markus 1977; Rumelhart 1980; Brewer and Treyens 1981; Garnham 1981; Holland 1985; Beals 1998). Schemata also allow individuals to develop expectations about the future: They are shaped differently depending on experience, and work to mediate our understanding of the world (Garro 2000). Thus, investigating schemata helps further expose the relations of ruling and how marginalized individuals negotiate their shaped reality, both psychologically and socially (Poulin and Gouliquer 2012). P-SEC also involves investigating cognitive and behavioral coping mechanisms used when facing complications. Examining the coping mechanisms helps reveal how practices or policies (i.e., the Organizational Moments) benefit the institution, but complicate the reality of the marginalized. The final step in the P-SEC approach is to use the findings to develop social change and policy recommendations that will improve the marginalized individuals' realities.

\section{Participants}

One hundred and thirteen ( $\mathrm{N}=113)$ women firefighters took part in this pan-Canadian study. All partici- 
pants were either current or past volunteer/part-time or career firefighters. Volunteer firefighters are usually compensated one way or another (e.g., honoraria or through tax exemption programs). The amount varies widely. In some jurisdictions (e.g., Quebec), the volunteer category does not exist as they are paid per emergency call and their work referred to as parttime. However, in none of these cases are they able to earn a living from this revenue. Participants were recruited through the use of advertisements within firefighting contexts (e.g., Women in Fire webpage, magazines and newsletter/discussion forums) and by the snowball technique (i.e., word of mouth). Participants ranged in age from 19 to 64 years $(\mathrm{M}=38.5$ years), and the time spent in the fire services ranged from 1 to 31 years $(M=10.34)$. Seventy women were volunteer/part-time, 18 were career/full-time, and 24 had experience with both volunteer/part-time and career positions. Height ranged from $152.20\left(5^{\prime}\right)$ to $188.98\left(6^{\prime} 2^{\prime \prime}\right) \mathrm{cm}\left(\mathrm{M}=167.64\right.$ or $\left.5^{\prime} 5^{\prime \prime}\right)$, while weight ranged from 110 to 250 pounds $(M=160.34)$. Eight women indicated that they were non-heterosexual, and 16 women identified as non-Caucasian.

\section{Interviews}

Semi-structured interviews were carried out in person, via telephone, or through online communication platforms (e.g., Skype), and lasted an average of two hours. Participants were asked to highlight, in chronological order, significant career events such as training, job-related performance tests and interviews, or promotions. These served as anchor points and helped guide the interviews (Gouliquer and Poulin 2005). Using anchor points as an outline, participants were asked to recount their firefighting experiences. Interviews were transcribed verbatim and analyzed according to P-SEC analysis (i.e., thematically and for Organizational Moments and their concomitant com- plications, schemata, coping strategies, and benefits to the institution). All identifying information (names, places) have been changed or removed to protect the women firefighters. In the following section, the Organizational Moment, Othering, is explored.

\section{Results}

\section{Organizational Moment: Othering}

As described earlier, Othering is the systematic stigmatization of an out-group by an in-group as a means to maintain the hegemony (Tsouroufli et al. 2011). Men have been the dominant in-group within the fire services since its inception and women firefighters are considered outsiders. Specifically, it is white heterosexual men who dominate and impose a particular masculine identity within the social environment of firefighting (see: Connell 1995 for a discussion on multiple different masculinities). Women do not fit the stereotype of the firefighter and they are marginalized through an Othering process. Women do not need to display so-called "feminine characteristics" (e.g., be physically and psychologically weak, wear make-up, or be pregnant) to be Othered; the assumption is that by default, they are lacking in "male characteristics." Other characteristics such as sexual orientation, age, ethnicity/race, stature (i.e., height and weight) can also be stigmatized. Notably, the Othering process is dynamic and interactive rather than additive: Characteristics are often Othered together, creating an intersectionality of oppression (Culp 1994). All participants spoke of instances of Othering and Rachael's quote exemplifies this point:

I think that the biggest negative is always feeling like the outsider... If the guys need help on a course they're teaching, they tend to choose each other...I'm 
never the one chosen or asked. It's isolating. [Rachael, 38, Caucasian, career \& volunteer/part-time]

\section{Complications}

The process of Othering created complications for women firefighters. The most notable ones were:

1) Discrimination, 2) Hostile Working Conditions,

3) Self-Doubt, and 4) Weakened Firefighter Identity.

\section{Discrimination}

Discrimination can be seen as dynamic and existing along three dimensions: Subtle (ambiguous) or overt (visible and structured), formal (i.e., job-related) or interpersonal (i.e., socially-related), and intentional or unintentional (Van Laer and Janssens 2011; Jones et al. 2016; Jones et al. 2017). The process of Othering is usually underpinned with acts of discrimination. For the women firefighters, discrimination began at the start, during the recruitment process. According to Diane, new women applicants struggled with gender-based discrimination:

There were several people who applied [for the firefighting job], some of which were female. All the females got rejected. There were some key players, key stakeholders, and senior officers in the fire department. Town council decided that they needed to look into this because it is discrimination [but the women still] didn't even get a foot in the door. [Diane, 37, Caucasian, volunteer/part-time]

Women spoke of discrimination that spanned throughout their career, as exemplified by the gendered bullying Hariot received:

I had much experience with him being a bully [the Deputy Chief]. He would overlook us [women fire- fighters] for tasks or roles, and make negative comments about the capability of women...He made us feel guilty for it [needing uniforms that fit], and then he bullied us. [Hariot, 28, Caucasian, career \& volunteer/part-time]

Discrimination pertaining to non-gender-related characteristics, such as age and sexual orientation, was also described. Michelle recounted instances of subtle discrimination where her achievements went unacknowledged by her men colleagues because of her age:

I'd always win [competitions] in my age category...I would always be about sixth or seventh overall. But, because I was in the over-forty category, I would always be in the top three. They [men colleagues] wouldn't even mention it. They would never say anything. They didn't want to. [Michelle, 47, Caucasian, volunteer/part-time]

Instead of being treated like typical women, women with non-heterosexual orientations (e.g., lesbian, bisexual) were stereotypically perceived as possessing more masculine traits and capabilities and thus, somehow accepted as pseudo-men. As Jen's quote illustrates, the cost of being accepted, even if only symbolically, is the complicit obliteration of women's gender and sex identity.

This woman walks by in front of the truck and all the guys in the truck have a conversation about whether or not they'd have sex with her. They don't even bat an eye about saying that in front of me. I think partly because I am a lesbian in their eyes, even though I tell them I date men, too. But, it's easier for them to think of me as a lesbian. They think that I'm in on it...sex with that woman, too. [Jen, 36, Caucasian, career, volunteer/part-time] 
Older women and women minorities were perceived and treated by their men colleagues as "special" because everyone believed that the physical and academic standards had been lowered so that they could pass. These perceptions were internalized and affected women firefighters for the entirety of their careers as they often felt and were identified as less capable and intelligent than their men colleagues. Age and racial Othering is illustrated in the quotes of Natasha and Qadia, respectively:

I think that it was bad enough being the first woman, but when I was hired, I was the oldest person ever hired there. I was forty and so there was all this discrimination from all sides. [Natasha, 57, Caucasian, career]

Just because we're minorities doesn't mean we're stupid. They set the entrance exam at $75 \%$, where the white male still needed 90\%. We're [minorities] not dumb. [Qadia, 49, non-Caucasian, career]

Further complicating these women's lives was the discrimination they faced when actually displaying feminine traits or characteristics such as pregnancy. Career women firefighters are protected by formal workplace legislation for pregnancy and maternity; however, they had issues with not being given meaningful light duties during their pregnancy. For volunteer/part-time firefighters, there is no protection and women are more at the mercy of their departments. The quote illustrates the limited (non-existent) choices they faced:

A leave of absence in my department is six months long. That doesn't even accommodate being off with a baby, let alone being advanced in pregnancy and not being able to do heavy lifting. And if you take a leave of absence longer than six months, they re- quire that you do your whole recruit training all over again. [Nadia, 44, Caucasian, volunteer/part-time]

Most volunteer/part-time women firefighters leave the volunteer fire service for years or permanently due to the lack of accommodation related to pregnancy and childcare.

The discursive messages that men were communicating to their women colleagues were another deeper and implicit layer of discrimination. The experience of Danielle in the next quote illuminates how, in addition to treating women differently because of their gender, men firefighters treated them differently based on physical attributes.

Because of my stature, and I'm talking about my height, I do get treated differently...This one night we were out, it was so slippery that as soon as you stepped off the fire truck, you fell. Another female firefighter fell, she's heavier, and the guys just laughed. I had to go out, same thing happened, I fell. But, instead of laughing, they all rushed off the truck to pick me up. [Danielle, 49, non-Caucasian volunteer/part-time]

Thus, the women firefighters who embodied the ideal woman stereotype (i.e., pretty, petite, and feminine) were treated as fragile, weak, and in need of help (i.e., with benevolent sexism). The men's gender performance illustrated in Danielle's quote serves to bolster the masculine hero firefighter stereotype and the hegemony of masculinity and men. It also serves to divide women as women who did not embody the ideal feminine stereotype were punished (e.g., mocked), while the others were rewarded with benevolent sexism for their perceived femininity.

Volunteer women firefighters are also discriminated against as their status is not valued and they do not 
have "social capital" (Yarnel and Dowler 2002). Consequently, they are not chosen to attend firefighting conferences and social gatherings. Pauline's example illustrates how the volunteer firefighting status can lead to less workplace opportunities.

There was an e-mail out from head office saying that there was an international women's firefighting conference and if anybody wanted to apply they couldcareer or volunteer. I put my application in and my friend as well, and it turned out we were the only two volunteer females who applied. We were not chosen to go. It was all career...And I heard through the grapevine that we weren't picked because we weren't "qualified." [Pauline, 46, non-Caucasian, volunteer/ part-time]

What is not clear in such incidents is the ambiguity that multiple identities can create. It is simply untraceable and unclear if it was the volunteer status, gender, racial identity, or age or a combination that influenced the selection process. The above findings illustrate that it is often the case with discrimination when multiple identities intersect with gender.

\section{Hostile Working Environment}

Hostile working environments are characterized by repeated adverse verbal (e.g., insulting remarks, ridicule, teasing, verbal abuse, degradation of one's effort and work) and physical acts (e.g., isolation, social exclusion) (Einarsen, Raknes, and Matthiesen 1994). Multiple women, such as Dale and Ivy, reported negative verbal occurrences, which led to feelings of fear:

They [men colleagues] said, "Wait until we bend you over. Either way, we are gonna break you!" The next day, I was coming down to go through the bay and the guys were literally talking about how they were going to corner me to make sure that I would get so scared that I would leave. The words were extremely crude and explicit. I actually got scared! [Dale, 40, Caucasian, career \& volunteer/part-time]

This one instructor who did not want me there pulled me aside when I said, "I need a point of clarification." And he told me to shut up, and he tried to incite me to hit him. He had his finger in my face...I started to walk away from him, and he says, "Well, I'm gonna bring you up on charges, basically get you into trouble." [Ivy, 45, Caucasian, career]

Many women reported sexual harassment and some sexual assault. However, for fear of being disbelieved and ostracized by their colleagues and the fire services' administration, women kept quiet about the harassment and sexual assault with the hope that the situation would change. However, this stratagem often resulted in men taking advantage of the situation, as Colleen's quote illustrates:

At fire training, out of the blue, he [Deputy Chief] exposed himself to me...I stayed my distance away from him for quite some time. Then, when I'd been around him again, he'd seem fine...So, I come in on a Saturday and he was in the office. I walked in and he went around behind me and shut the door and then forced himself on me [sexually]. [Colleen, 35, Caucasian, volunteer/part-time]

Colleen did not report the assault for years.

\section{Self-Doubt}

Many participants reported feelings of self-doubt and a loss of confidence. The duration of time each woman firefighter was part of the fire services, 
whether one or twenty years, was not a factor. Although women knew that they could handle the demanding physical and mental aspects of the occupation, many had moments when they believed that they were not good enough to be a firefighter. Participants spoke about the hardships from having experienced this self-doubt. As illustrated by Paige, who had injured herself while trying to "keep up with the big boys":

I have my days where I still doubt my ability to be here, even though I've been here for fourteen years...I have my doubts as to whether or not I still belong. [Paige, 44, Caucasian, career]

According to Denise, the discrimination from her men colleagues plummeted her confidence:

You go to work and it's always like walking on eggshells. You watch your back all the time. You don't know if you're going to get blamed for something or if you're going to do a good job. At the end, [my] confidence went from really confident, thinking that I could do anything, to almost thinking, "Oh my God, I'm not a good firefighter at all." [Denise, 34, Caucasian, career \& volunteer/part-time]

The intersection of gender and age also played a role in women firefighters' feelings of self-doubt. Instead of doubting that they could do the job because of age or gender, they identified that both factors were an issue. Whether they were older when they joined the fire services or later in their career, self-doubt plagued the women. Ivy and Cecilia's quotes indicate how many of the women negotiated their doubts:

I doubted when I first got into recruit training if I could physically do it: I was in better shape than over half the people in the class. But, it was my own downfall that made me doubt-you get so old, and then you question. [Ivy, 45, Caucasian, career]

There's definitely been situations where it becomes more of a self-doubt. You wonder, "Am I a weak link here? Am I helping or am I slowing the process down?" I think you kind of always have [self-doubt] in the back of your head, "What are the guys thinking?" [Cecilia, 44, Caucasian, career \& volunteer/part-time]

\section{Weakened Firefighter Identity}

The social perception is that firefighters are men. Thus, because women do not fit the typical masculine firefighter stereotype, they are often undermined internally (i.e., within the fire services) and externally (i.e., outside of the fire services). When undermined internally, coworkers, city management, and the government refuse to treat women as firefighters. Yvette's example speaks to how explicitly, through job assignments, leaders can undermine women's credibility as a firefighter:

They [men colleagues] don't want females in the fire department. They want it to be just a guy's thing, and it's to get them to let me do things. We had a big huge rolling house fire and I am fully trained to go in and attack. I rolled up on scene, I went up to the new chief and said, "What do you want me to do?" And he said, "Go stand by that fire truck and watch it pour water." [Yvette, 24, Caucasian, volunteer/part-time]

When women are undermined externally, it can involve their family, friends, and the public. This process is illustrated by Rebecca and Vicki:

You still have people from the general public walking up and going, "Well, you're not a firefighter. You're 
a woman, you don't go fight fires."...They didn't think we are fighting fires and going to car accidents and riding in the big red trucks. [Rebecca, 43, Caucasian, volunteer/part-time]

When people think firefighter, they think $6^{\prime} 2^{\prime}$, big, burly guy coming with his axe. And when I jump off the truck, they're like, "What's going on?" [Vicki, 36, non-Caucasian, career]

Ultimately, women are treated and viewed as if they are not capable of doing the job.

\section{Schematic Analysis}

Participants evoked various schemata to make sense of the complications they experienced because of the Organizational Moment, Othering. Three of the most common schemata were: Old Boys' Club, Just the Way It Is, and Family.

\section{Old Boys' Club}

This schema consists of a hegemonic and historical understanding of why men treat women so poorly and why women are lacking in numbers in men-dominated occupations; it's an Old Boys' Club (Adams 2001; Gouliquer 2011; Walker and Bopp 2011-2012; Burdett 2017). Women firefighters evoked this schema to understand that the behaviors and attitudes of their men colleagues are deeply rooted in a sexist tradition that is generational in nature. Thus, the women evoked this schema to make sense of why men can still behave the way they do. As Holly and Anabel suggested:

It's an Old Boys' Club... I think a lot of what drives some of the guys to join is that it gets them out of the house, they're away from their wives, they can be- have as they want to and say the things they want and not have to worry. [Holly, 38, Caucasian, heterosexual, volunteer/part-time]

It's an Old Boys' Club and you are never going to belong. And the moment you think you belong, you're wrong. [Anabel, 32, Caucasian, heterosexual, career]

The use of the Old Boys' Club schema illustrated that women understood the powerlessness of their position, although by using it, the women were absolving the men of taking responsibility. The schema indicates that the culture and the treatment of women both remain marginalizing.

\section{Pseudo-Family}

Pseudo-families, according to Forsyth and Evans (2003), function as emotional and economic support groups, and are characterized by aggressive behaviors. Women evoke the Pseudo-Family schema to justify why the fire services are comprised of teasing and hazing behaviors. If firefighting is a Pseudo-Family, then many negative behaviors and comments are warranted as this is what is stereotypical of familial life. As Claudia suggests:

It really is like a large family. They're my brothers, my sisters, and we totally fight like siblings, too. I've had blowouts with some of them. I've had blowouts with my old Fire Chief. We butt heads, we deal with it, and then we move on. [Claudia, 29, Caucasian, volunteer/ part-time]

Bloodline connections among families are non-negotiable. However, if Fireservices embrace and display the mentality of a Pseudo-Family and behaves according to close group pressure rules (Forsyth and Evans 2003), this dynamic will result in group 
pressure and alliances that will tend to silence marginalized members. This is exactly the types of behaviors participants reported should not be inevitable. Accordingly, many women felt that nothing could be changed because one cannot betray their firefighting family. Bee and Evie's comments illustrate this mentality:

You have your ups, you have your downs. It's like a family. You can't really do much about it. They are yours. You gotta work with them. [Bee, 32, Caucasian, career]

We've very much a brother-and-sisterhood. You can choose your friends, but you can't pick your family, so you better get along because this is what it is. [Evie, 49, Indo-Canadian, volunteer/part-time]

The use of this schema by women firefighters indicates that women are recognizing their limited powerlessness in transforming this workplace into a professional environment and cognitively making do with it.

\section{Just the Way It Is}

As the firefighting culture is difficult to change, women see that everything within the fire services is Just the Way It Is. Although this schema is closely related to the Old Boys' Club and Pseudo-Family schemata, it differs in specifically drawing attention to the fire services' culture and its discriminatory and rigid mentality. Women utilize this schema to make sense of more punitive treatment (e.g., harassment, discrimination). Bree and Isa's quotes capture this aspect of the fire services:

Are there racial slurs? Oh, all the time. There's sexist jokes, too. Like, the racist jokes, I think it's just part of the culture. The swearing, the jokes, the crassness, it's all part of the culture. [Bree, 26, non-Caucasian, career]

Well, there's always forms of harassment, sexual harassment. Not in a negative actual touching type of way, but sometimes people's comments are a little too far. It is joking in a lot of cases... If you're sensitive, too hypersensitive, you wouldn't fit in. There is a culture and [the question is] do you want to be part of it, or do you not want to be part of the culture. [Isa, 37, Caucasian, career \& volunteer/part-time]

By using this schema, women are able to put up with the level of harassment and discrimination. By doing so, however, they undermine their own presence in the midst of fire services.

\section{Behavioral and Cognitive Coping Strategies}

Women utilized behavioral and cognitive coping strategies to negotiate the complications from the process of Othering. Four behavioral and two cognitive coping strategies were identified. Behavioral coping strategies included: Proving Yourself, Denying, Adopting Different Techniques, and Training for Strength. Cognitive coping strategies included: Pride and Firefighters; Not Firemen.

\section{Behavioral: Proving Yourself}

Many women talked about the need to prove that they could do the work and survive the culture. According to Kim:

Whether it's realistic or not, once you prove yourself, I think you're good to go. They're watching and they're gonna see, and then you start to prove yourself. You're competent, you know your stuff, and 
you're right in there with them-you're not hanging back. [Kim, 39, Caucasian, career]

\section{Behavioral: Denying}

To overcome negative treatment from their men colleagues, women pretended that they were not bothered by the negative comments and behaviors to which they were directly or indirectly exposed. Alice and Johanne's comments exemplify denying as a means of coping and underscores women's sense of powerlessness in the fire services:

You've got to walk a fine line of being one of the guys... you don't want to make them [men colleagues] uncomfortable in their fire house. They need to be comfortable, so you kind of ignore a lot of the things you hear. [Alice, 46, non-Caucasian, volunteer/part-time]

I know that I chose that profession [firefighting], so I just don't react to it [language, discrimination] at all... I don't want to stir things up, but I am a woman in a man's world, so there's a certain amount of things that you just ignore or try to deal with it. [Johanne, 32, Caucasian, career]

\section{Behavioral: Adopting Different Techniques}

Although women firefighters are both mentally and physically strong, many tools, equipment, and techniques are designed for and by men. Thus, physical testing, in addition to being based on men's strengths, is accomplished in a firefighting environment built to accommodate men's height, strengths, and techniques. Women often spoke of changing how the task was done so that they could accomplish the work. As Lenore's statement suggests, they had to adopt different ways of doing what seemed like an easy task for the men:
The sledgehammer was hitting me in the crotch and I was losing all my power. I had to stand and hold the sledgehammer differently to be able to move this thing quickly. Whereas the guys' techniques, they could stand up and do it no problem. [Lenore, 29, Caucasian, career \& volunteer/part-time]

\section{Behavioral: Training}

Strength training was another commonly exhibited coping strategy for women in the fire services. Many women firefighters centered their lives around the gym to improve their strength and to avoid being labeled with the weaker sex stereotype.

I think it's a self-fulfilling prophecy that you worry that you'll be looked at as weaker, so I just want to make sure that my strength is to a place where I'm comfortable that I could do any of the tasks required...I'm definitely aware that my strength, compared to a lot of men, isn't as good, so I work hard on that in the gym. I do a lot of weight training. [Carol, 26, non-Caucasian, career]

\section{Cognitive: Pride}

Being proud of accomplishments was a cognitive strategy utilized by women to counteract Othering. Although this seems like a positive adaptive coping strategy, it had negative undertones. Women felt proud of their work, but they saw themselves as doing well as a woman in a men-dominated occupation instead of just doing well. The next quote by Ultana illustrates this sentiment:

I think as a woman, you have a little bit more pride because you're a woman doing a job that's ninety-five percent male-dominated...Knowing I'm one of three women in my department that's doing this job, it's 
a huge sense of pride and accomplishment. [Ultana,

38, Caucasian, career \& volunteer/part-time]

In addition to gender, age intersected with women feeling pride in abilities as a firefighter. Like Jady, participants expressed that they were proud of being able to continue to be a firefighter despite their age.

It is a reward for yourself just to be able to do it. So, when I come out and I've done a good job, I feel proud of myself. I can still do this really hard work and I'm an old woman now. [Jady, 37, Caucasian, career \& volunteer/part-time]

Although 37 is not typically considered old, the high expectation placed on strength and physical performance influences the intersection of age and gender in firefighting. This remains the case today despite the fact that the act of fighting fires does not dominate the actual work of firefighters. In summary, although they are faced with multiple oppressive factors, women combat being Othered with their pride of being a firefighter. As revealed by Ulie:

I'm proud of it. The title firefighter means a whole lot more to me. If I have to give a biography, I always put that in there because I do think that it's important. One of my friends was like, "Well, I'm gonna introduce you, what should I say?" "Career Firefighter." And she's like, "Well, anything else?" "No, that's enough." [Ulie, 36, non-Caucasian, career]

\section{Cognitive: Firefighters; Not Firemen}

To contest the hegemony and stereotype that only men are firefighters, women coped by rejecting the label "firemen" and replacing it by "firefighters." As noted previously, women faced direct and indirect questionning regarding the legitimacy of their presence as firefighters, both internally and externally to the fire services. Thus, they show defiance towards the use of labels which excludes them. Madelaine's quote demonstrates their active attempts to reframe and change cognitions:

There have been times where little girls come over to me and they'll say, "It's so cool that you get to be a fireman!” [I say,] “Well, no. I'm not a man, but I'm a firefighter." [Madelaine, 23, Caucasian, volunteer/ part-time]

\section{Benefits to the Fire Services and the White Heterosexual Man}

As the above findings illustrate, Othering is embedded in policies and practices of the fire services that are assumed to be gender neutral, and have the same impact on all firefighters. However, this is not the case. They were developed without women or individuals who are not part of the normative group. Thus, they tend to complicate the reality of marginalized individuals, while benefiting those who are members of the norm and the ruling apparatus. Two benefits for the fire services and the dominant group of men emerged: 1) Medical Calls, and 2) Tokenism.

\section{Medical Calls}

In more recent years, the types of work accomplished in the fire services have expanded. For example, historically firefighters did not typically respond to emergency medical calls or car accidents. This work, however, has not been equally distributed between men and women. Women are encouraged and pushed into the caring and nurturing role, which further divides the force and reinforces gen- 
der roles. Women spoke about their men colleagues' ineptitude and resistance to doing work that was perceived as feminine or that involved working with women victims. Kim and Natasha's comments illustrate what the women usually encountered during these types of calls:

The guys will shove me to the door on certain female-type calls. Like the pregnancies and the vagina problems, and then the girly problems... They shove me to the door and they stand by the door. [Kim, 39, Caucasian, career]

On medical calls, if there was somebody having a heart attack and we had to do CPR, and the spouse was there, the guys would always push me over to the spouse and say, "Natasha, go deal with her. You're better at that."[Natasha, 57, Caucasian, career]

Several participants, such as Valerie, were asked to join the volunteer fire services because men did not want to do some of the medical calls:

“Well, why don't you just join? 'Cause we could use you on the medical calls. You know how to do all the medical calls, and we don't like to do them." [Valerie, 41, Caucasian, career \& volunteer/part-time]

The women viewed their presence in firefighting as a valuable asset for the institution. They believed that their presence helped the fire services avoid potential lawsuits from sexual harassment claims. Catherine's quote exemplifies this benefit to the institution:

I think we're a big benefit for the fire department, especially dealing with female patients. That takes a lot of liability away when the guys are working there and then the woman says, "He touched me." So, there's no risk of having a sexual assault case against someone. [Catherine, 27, Caucasian, career]

\section{Tokenism}

By putting women firefighters in the media, fire services promote the image that they care about women. According to Zimmer (1988:65), "token" refers "to persons (usually women or minorities) who are hired, admitted or appointed to a group because of their difference from the other members, perhaps to serve as 'proof' that the group does not discriminate against such people." In many incidents, the women talked about how the fire services' administration used them to ensure that benefits (e.g., acquiring further funding, positive publicity) ensued. However, using women as tokens overshadows what is really going on within the fire services. This occurred in both the volunteer and career fire services as the following quotes illustrate:

Our administration has always wanted to parade the female firefighters. Parade us around like show ponies. You know, "Look at us! Look how many female firefighters we have. Aren't we great?" [Miriam, 37, Caucasian, career]

For management's perspective, I look good for them. It was in the media when I finally got on because I was non-Caucasian and a career [firefighter]. [Zaki, 36, non-Caucasian, career]

\section{Discussion/Conclusion}

Othering women and other marginalized groups in men-dominated professions is commonplace as it provides advantages for the dominant group (White heterosexual men) (Paechter 1998; Staszak 2008; Hudson and Melber 2014). The Canadian fire 
services is one of these professions that has and continues to exclude women from their ranks and sites of power if they do get in (Weiner 1994; Poulin et al. 2018). As the above findings demonstrate, Canadian women firefighters, whether volunteer or career, are Othered. The complications, (i.e., 1) Discrimination, 2) Hostile Working Conditions, 3) Self-Doubt, and 4) Weakened Firefighter Identity) allowed the fire services, and thus White men, to maintain their dominant in-group status within the fire services. It also allowed the institution to routinely ignore the issues that women firefighters confront on a daily basis. The findings from this study indicate that women were harassed, alienated, stigmatized, and discriminated against by their men colleagues. For women, the fire halls and stations were often hostile working environments. This, in turn, led them to self-doubting their abilities to be firefighters, which is compounded by other characteristics such as age, minority, and stature. In addition to not being accepted by their men colleagues as "real" firefighters, women firefighters were confronted with a persistent external gaze of the general public that negated their existence as firefighters.

Much of the research on women firefighters previously was conducted in other Western countries (e.g., AUS, UK, US: Yoder and Aniakudo 1996; Yoder and Aniakudo 1997; Yoder and McDonald 1998; Wang and Kleiner 2001; Yoder and Berendsen 2001; Batty and Burchielli 2011; Perrott 2016;), but there are stark similarities and contrasts in content. Although previous studies focused on women firefighters' experiences, many have only investigated specific intersections (e.g., gender, sexuality, and occupational group; Wright 2016; gender, sexuality, and class; Wright 2011; sexuality and gender; Wright 2008; race and gender; Yoder and Aniakudo 1997). Moreover, while Othering underpins much of the past stud- ies, to our knowledge, no study has directly identified that the intersectionality of different identities/ statuses is connected to Othering. The strength of this paper is the highlighting of the multiple intersections (e.g., gender, race/ethnicity, age, firefighter title, feminine characteristics, stature).

Barriers to inclusion within the fire services were highlighted by participants. Women described their experiences with exclusion from events, hyper-masculine criticisms and adverse behaviors, the denial of all femininity, and hyper-awareness of minority status(es). Women who exhibited "undesirable" characteristics, such as those associated with femininity, pregnancy, motherhood, smaller stature, appearance, or strength/weakness, were Othered by their men colleagues through the use of gendered and psychological violence. Although instances of sexual assault were present in the data, many of the negative behaviors were psychological in nature. This supports Staszak's (2008) notion that non-violent behaviors are more common to marginalized groups than physically violent ones. The process of Othering in the fire services produced two outcomes: 1) It inhibited solidarity between the dominant and marginalized groups and specifically perpetuated women's exclusion, and 2) it interfered with the women in the fire services from getting positions of power (Staszak 2008).

Women have and continue to struggle with reporting instances of discrimination and harassment within men-dominated occupations (Chetkovich 1997; Poulin et al. 2018). Participants in this study avoided reporting their men colleagues due to fear of ostracization, a lack of trust in the fire services' system of reporting, or potentially exacerbating the situation. When women reported these instances, they were often ignored by the administration, harassed further by their colleagues, or reprimanded 
for attempting to report a colleague. Participants developed and employed similar behavioral and cognitive ways of making sense of and dealing with the Othering. As opposed to most strategies they used, when they cognitively redefined themselves as Firefighters; Not Firemen, the women actively challenged perceptions about women's roles in firefighting. Investigating Othering and the intersectionality of factors using the P-SEC methodology was a novel approach to analyzing women firefighters' experiences in the Canadian fire services. Until now, there has been limited research focusing on women's experiences of Othering that also takes into consideration the various intersectionalities that women embody.

\section{Policy/Social Change Recommendations}

The findings from the present study indicate that the policies, practices, and culture of fire services need to be improved and changed to overturn the negative outcomes that women firefighters encounter in their daily work. The pressure to fit in with the dominant in-group leaves women firefighters with little to no choices when it comes to reporting harassment and discrimination, let alone more minor transgressions such as language and work assignments. The following policy and social change recommendations have been developed based on women's experiences in the fire services.

The hiring policies and practices should be monitored more closely with respect to equity principles under the Canadian Employment Equity practices. The fire services in Canada are administratively and functionally very decentralized. Firefighting is fractured and no national organization or fire protection exists. For the career firefighters, cities are the employer and for the volunteers, they report to provincial bodies. In both instances, a national body of quality control that has the financing and political power to control the periphery would bring a more uniform way to deal with the issue of under-representation of women and minorities. Enacting a more central body across Canada could help alleviate the diversity-related issues currently observed within the fire services.

The fire services, whether volunteer or career, need to develop clearly delineated policies on dealing with harassment and discrimination within their departments. Having a zero-tolerance policy for all forms of harassment-verbal (e.g., derogatory remarks) or physical (e.g., unwanted physical contact, sexual assault) (Saguy 2000)-in every fire station will promote a safer environment. The consequences of violating the policy should be monitored and reported to the national body. Additionally, women need to be educated about their options for reporting harassment and discrimination; this would enable them to make difficult choices, without feeling guilty or afraid of the consequences (Poulin et al. 2018). In keeping with this recommendation, having a reporting and aid system located outside of the firefighting hierarchy and city management would help increase women's confidentiality and confidence in reporting instances of discrimination and harassment.

Testing and evaluative policies should be evaluated with a gendered-diversity lens. Testing should reflect what the job entails, as some tests are not indicative of real-life firefighting environments. For example, firefighters never work alone; therefore, individually dragging a 200-250-pound dummy is seemingly less relevant than effective team work. Balancing the training (individualized, standardized, physical, and academic standards) with a recognition and valuation of the benefits that a diverse workforce can bring should be prioritized. 
If the fire services and men are committed to supporting women and other marginalized groups, the cultural environment, ideals, practices, and policies need to be transformed. The findings in this study indicated that women bear the brunt of entrenched complications to survive in a profession that they are passionate about. Thus, it is important that these issues be addressed to encourage women and minorities' inclusion within the fire services. Without the

\section{References}

Acker, Joan. 1990. “Hierarchies, Jobs, Bodies: A Theory of Gendered Organizations." Gender \& Society 4(2):139-158.

Adams, Kacey. 2001. Women in Senior Police Management (Report series, no. 138.2). Payneham: Australasian Centre for Policing Research.

Ainsworth, Susan, Alex Batty, and Rosaria Burchielli. 2014. "Women Constructing Masculinity in Voluntary Firefighting." Gender, Work and Organization 21(1):37-56.

Bailyn, Lotte. 2006. Breaking the Mold: Redesigning Work for Productive and Satisfying Lives. Ithaca, NY: Cornell University Press.

Bannerji, Himani. 2000. The Dark Side of the Nation: Essays on Multiculturalism, Nationalism, and Gender. Toronto: Canadian Scholars' Press.

Batty, Alex and Rosaria Burchielli. 2011. "Out of the Frying Pan, into the Fire? Persistent Gender Barriers in Australian Fire-Fighting and Challenges for HRM." Asia Pacific Journal of Human Resources 49(3):308-324.

Beals, Diane E. 1998. "Reappropriating Schema: Conceptions of Development from Bartlett and Bakhtin." Mind, Culture, and Activity 51:3-24.

Beatson, Ruth and Jim McLennan. 2005. “Australia's Women Volunteer Firefighters: A Literature Review and Research Agenda." Australian Journal on Volunteering 2:18-27.

Bem, Sandra L. 1983. "Gender Schema Theory and Its Implications for Child Development: Raising Gender-Aschematic Children in a Gender-Schematic Society." Signs 8:598-616. commitment to provide a more diverse fire services workforce, their experiences will continue to be ignored, which will further discourage women and other diverse groups from entering such men-dominated occupations. Ultimately, changing the atmosphere by eliminating Othering practices, and altering the culture, archetypes, values, and policies will enable firefighting in Canada to become a more positive and productive workplace for all.

Bem, Sandra L. 1993. The Lenses of Gender: Transforming the Debate on Sexual Inequality. New Haven, CT: Yale University Press.

Bendl, Regine. 2008. "Gender Subtexts - Reproduction of Exclusion in Organizational Discourse." British Journal of Management 19(1):S50-S64.

Bleijenbergh, Inge E., Marloes van Engen, and Claartje Vinkenburg. 2011. "Othering Women: Fluid Images of the Ideal Academic." Equality, Diversity, and Inclusion: An International Journal 32(1):22-35.

Bransford, John D. and Marcia Johnston. 1972. “Contextual Prerequisites for Understanding: Some Investigations of Comprehension and Recall." Journal of Verbal Learning and Verbal Behaviour 11:717-726.

Brewer, William F. and James Treyens. 1981. "Role of Schema in Memory for Places." Cognitive Psychology 13:207-230.

Broome, Rodger E. 2012. “The Psychology of 'Othering' and the Fears of Feminizing the Fire Services through Gender Inclusiveness." iWomen's Member Newsletter 1(45):7-9.

Burdett, Freda. 2017. When Practices Embody Sexism: The Experience of Ontario Women Correctional Officers. Doctoral Dissertation. Retrieved June 19, 2020 (file:///C:/Users/kamma/ Downloads/Dissertation\%20F.\%20Burdett\%20September\%20 2017.pdf).

Carby, Hazel. 1997. “On the Threshold of Woman's Era: Lynching, Empire, and Sexuality in Black Feminist Theory." Pp. 330343 in Dangerous Liaisons: Gender, Nation, and Postcolonial Per- 
spectives, edited by A. McClintock, A. Mufti, and E. Shohat. Minneapolis, London: University of Minnesota Press.

Chetkovich, Carol A. 1997. Real Heat: Gender and Race in the Urban ire Service. New Brunswick, NJ: Rutgers University Press.

Connell, Raewyn. 1995. Masculinities. Cambridge: Polity Press.

Craig, Jane M. and Rick Jacobs. 1985. "The Effect of Working with Women on Male Attitudes toward Female Firefighters." Basic and Applied Social Psychology 6(1):61-74.

Culp, Jerome. 1994. “Colorblind Remedies and the Intersectionality of Oppression: Policy Arguments Masquerading as Moral Claims." New York University Law Review 69(1):162-196.

Einarsen, Ståle, Bjrn Raknes, and Stig Matthiesen. 1994. “Bullying and Harassment at Work and Their Relationships to Work Environment Quality: An Exploratory Study." European Journal of Work and Organizational Psychology 4(4):381-401.

Flynn, Kevin. 2000. “Despite Recruiting, few Women Do Well in Firefighter Tests." New York Times, B-1, February 03.

Forsyth, Craig J. and Rhonda D. Evans. 2003. “Reconsidering the Pseudo-Family/Gang Gender Distinction in Prison Research." Journal of Police and Criminal Psychology 18:15-23.

Garnham, Alan. 1981. "Mental Models as Representations of Text." Memory and Cognition 9:560-565.

Garro, Linda C. 2000. "Remembering What One Knows and the Construction of the Past: A Comparison of Cultural Consensus Theory and Cultural Schema Theory." Ethos 28(3):275-319.

Gates, Gary J. 2011. How Many People Are Lesbian, Gay, Bisexual, and Transgender? Los Angeles: The Williams Institute.

Gingrich, Andre. 2004. “Conceptualizing Identities.” Pp. 3-17 in Grammars of Identity/Alterity -A Structural Approach, G. Bauman and A. Gingrich. Oxford: BergHahn Press.

Goffman, Erving. 1960. "Characteristics of Total Institutions." Pp. 449-479 in Identity and Anxiety: Survival of the Person in Mass Society, edited by M. R. Stein, A. J. Vidich, and D. M. White. Glencoe, IL: Free Press.

Gouliquer, Lynne. 2011. Soldiering in the Canadian Forces: How and Why Gender Counts! Doctoral Dissertation, McGill University, Canada. Retrieved June 19, 2020 (http://www.collectionscanada. gc.ca/obj/thesescanada/vol2/QMM/TC-QMM-96779.pdf).
Gouliquer, Lynne and Carmen Poulin. 2005. “For Better and for Worse: Psychological Demands and Structural Impacts on Gay Servicewomen in the Military and Their Long-Term Partners." Pp. 323-335 in Doing Ethnography: Studying Everyday Life, edited by D. Pawluch, W. Shaffir, and C. Miall. Toronto: Canadian Scholars Press.

Greenberg, Amy. 1998. Cause for Alarm: The Volunteer Fire Department in the Nineteenth Century City. Princeton, NJ: Princeton University Press.

Griffith, John C. et al. 2015. "Replication of the 2008 Report Card Women in Firefighting." Journal of American Academy of Business 21(1):26-32.

Harding, Sandra. 1987. Feminism and Methodology. Bloomington, IN: Indiana University Press.

Haynes, Hylton J. G. and Gary Stein. 2016. "U.S. Fire Department Profile - 2014." National Fire Protection Association $1-16$.

Holland, D. 1985. “From Situation to Impression: How Americans Get to Know Themselves and One Another." Pp. 389-411 in Directions in Cognitive Anthropology, edited by J. Dougherty. Chicago: University of Illinois Press.

hooks, bell. 2000. Feminist Theory: From Margin to Centre. Cambridge, MA: South End Press.

Hudson, Heidi and Henning Melber. 2014. "Contextualising African Identities, Othering and the Politics of Space." African Insight 44(1):1-6.

Hughes, Karen D. 1995. "Women in Non-Traditional Occupations." Perspectives on Labour and Income, Statistics Canada, Catalogue 75-001E 14-19.

Hulett, Denise M. et al. 2008a. “Enhancing Women's Inclusion in Firefighting in the USA. The International Journal of Diversity in Organisations, Communities \& Nations 8(2):189-207.

Hulett, Denise M. et al. 2008b. A National Report Card on Women in Firefighting. Madison, WI: International Association of Women in Fire \& Emergency Services.

Jahnke, Sara A. et al. 2012. "The Health of Women in the US ire Services." BMC Women's Health 12(39):1-12.

Jensen, Sune Q. 2011. “Othering, Identity Formation and Agency." Qualitative Studies 2(2):63-78. 
Jones, Kristen P. et al. 2016. “Not So Subtle: A Meta-Analysis of the Correlates of Subtle and Overt Discrimination." Journal of Management 42:1588-1613.

Jones, Kristen P. et al. 2017. "Subtle Discrimination in the Workplace: A Vicious Cycle." Industrial and Organizational Psychology 10(1):51-76.

Judd, Patricia C. and Patricia Oswald. 1997. “Employment Desirability: The Interactive Effects of Gender-Typed Profile, Stimulus Sex, and Gender-Typed Occupation." Sex Roles 37(7/8):467-476.

Klassen, Thomas R. and C. T. Gillin. 2005. "Legalized Age Discrimination." Journal of Law and Social Policy 20:35-51.

Lewis, Suzan. 1997. “'Family Friendly' Employment Policies: A Route to Changing Organizational Culture or Playing about at the Margins?" Gender, Work and Organization 4(1):13-23.

Lister, Ruth. 2004. Poverty. Cambridge: Polity Press.

Markus, Hazel. 1977. "Self-Schemata and Processing Information about the Self." Personality and Social Psychology 35(2):63-78.

Martin, Susan E. 1990. On the Move: The State of Women in Policing. Washington: Policy Foundation.

McLennan, Jim and Adrian Birch. 2006. "Survey of South Australian Country Fire Service Women Volunteers: South Australian Country Fire Service Report Number 2006: 1. Bushfire CRC Enhancing Volunteer Recruitment and Retention Project (D3)." Australian Journal of Volunteering 11(2). Retrieved June 19, 2020 (https://search.informit.com.au/documentSummary;d$\mathrm{n}=323542320140550$;res=IELHSS).

Paechter, Carrie. 1998. Educating the Other: Gender, Power and Schooling. London: Falmer Press.

Paragg, Jillian. 2015. “'Canadian-First': Mixed Race Self-Identification and Canadian Belonging." Canadian Ethnic Studies 47(2):21-44.

Perrott, Tamika. 2016. "Beyond 'Token' Firefighters: Exploring Women's Experiences of Gender and Identity at Work." Sociological Research Online 21(1):1-14.

Pettigrew, Thomas F. and Roel Meertens. 1995. "Subtle and Blatant Prejudice in Western Europe." European Journal of Social Psychology 25(1):57-75.
Poulin, Carmen and Lynne Gouliquer. 2012. "A Feminist Interdisciplinary Methodology: The Psycho-Social Ethnography of the Commonplace (P-SEC)." Non-published manuscript.

Poulin, Carmen, Lynne Gouliquer, and Alissa Moore. 2018. "Pompiers: La passion du feu et le prix à payer." Pp. 209249 in Enjeux humains et psychosociaux du travail, edited by J. Douesnard. Québec: Presses de l’Université du Québec.

Rapoport, Rhona et al. 2002. Beyond Work-Family Balance. Advancing Gender Equity and Workplace Performance. San Francisco: Jossey-Bass.

Riach, Kathleen. 2007. “'Othering' Older Worker Identity in Recruitment." Human Relations 60(11):1701-1726.

Riggins, Stephen H. 1997. "The Rhetoric of Othering." In The Language and Politics of Exclusion - Others in Discourse, edited by S. H. Riggins. Thousand Oaks, CA: Sage Press.

Rumelhart, David. 1980. "Schemata: The Building Blocks of Cognition." Pp. 33-58 in Theoretical Issues in Reading Comprehension: Perspectives from Cognitive Psychology, Linguistics, Artificial Intelligence, and Education, edited by R. J. Spiro, B. C. Bruce, and W. F. Brewer. Newark, NJ: Lawrence Erlbaum Associates.

Saguy, Abigail C. 2000. “Employment Discrimination or Sexual Violence? Defining Sexual Harassment in American and French Law." Law \& Society Review 34(4):1091-1128.

Said, Edward. 1978. Orientalism. London: Routledge \& Kegan Paul.

Sheppard, Coleen. 2001. “Of Forest Fires and Systematic Discrimination: A Review of British Columbia (Public Service Employee Relations Commission) v. B.C.G.S.E.U." McGill Law Journal/Revue De Droit De McGill 46:533-562.

Shuster, Melissa P. 2000. "The Physical and Psychological Stresses of Women in Firefighting." Work 15(1):77-82.

Sinden, Katryn et al. 2013. "A Qualitative Study on the Experiences of Female Firefighters." Work 45:97-105.

Smith, Dorothy E. 1987. The Everyday World as Problematic: A Feminist Sociology. Toronto: University of Toronto Press.

Smith, Dorothy E. 2005. Institutional Ethnography: A Sociology for People. New York: Rowman \& Littlefield Publishers. 
Staszak, Jean-François. 2008. “Other/Otherness.” International Encyclopedia of Human Geography 1-7.

Statistics Canada. 2017. "Occupation-National Occupational Classification (NOC) 2016 (693A), Highest Certificate, Diploma or Degree (15), Labour Force Status (3), Age (13A) and Sex (3) for the Labour Force Aged 15 Years and Over in Private Households of Canada, Provinces and Territories, Census Metropolitan Areas and Census Agglomerations, 2016 Census-25\% Sample Data. Statistics Canada Catalogue no. 98-400-X2016295. Retrieved June 19, 2020 (http://www.statcan.gc.ca).

Tsouroufli, Maria, Mustafa Ozbilgin, and M. Smith. 2011. “Gendered Forms of Othering in UK Hospital Medicine." Equality, Diversity, and Inclusion: An International Journal 30(6):498-509.

Van Laer, Koen and Maddy Janssens. 2011. “Ethnic Minority Professionals' Experiences with Subtle Discrimination in the Workplace." Human Relations 64: 1203-1227.

Walker, Nefretiti A. and Trevor Bopp. 2010-2011. “The Underrepresentation of Women in the Male-Dominated Sport Workplace: Perspectives of Female Coaches." Journal of Workplace Rights 15(1):47-64.

Wang, Shih-Yung and Brian Kleiner. 2001. "Sex Discrimination in Fire Fighting Organizations." International Journal of Sociology and Social Policy 21(8/9):175-183.

Weiner, Gaby. 1994. Feminisms in Education: An Introduction. Philadelphia: Open University Press.

Wright, Tessa. 2008. "Lesbian Firefighters: Shifting the Boundaries between 'Masculinity' and 'Femininity."' Journal of Lesbian Studies 12:103-114.

Wright, Tessa. 2011. “A 'lesbian advantage?' Analyzing the Intersections of Gender, Sexuality and Class in Male-Dominated
Work." Equality Diversity and Inclusion: An International Journal 30(8):686-701.

Wright, Tessa. 2016. “Women's Experience of Workplace Interactions in Male-Dominated Work: The Intersections of Gender, Sexuality and Occupational Group." Gender, Work E Organization 23(3):348-362.

Yarnel, Careen M. and Lorraine Dowler. 2002. "Who Is Answering the Call? Volunteer Firefighting as Serious Leisure." Leisure/Loisir 27(3-4):161-189.

Yoder, Janice and Patricia Aniakudo. 1996. “When Pranks Become Harassment: The Case of African American Women Firefighters." Sex Roles 35(5/6):253-270.

Yoder, Janice and Patricia Aniakudo. 1997. “'Outsider Within' the Firehouse: Subordination and Difference in the Social Interactions of African American Women Firefighters." Gender E Society 11(3):324-341.

Yoder, Janice and Patricia Aniakudo. 2001. “The Responses of African American Women Firefighters to Gender Harassment at Work." Sex Roles 32(3/4):125-137.

Yoder, Janice and Lynne Berendsen. 2001. “'Outside Within' the Firehouse: African American and White Women Firefighters." Psychology of Women Quarterly 25:27-36.

Yoder, Janice and Theodore McDonald. 1998. "Measuring Sexist Discrimination in the Workplace: Support for the Validity of the Schedule of Sexist Events." Psychology of Women Quarterly 22:487-491.

Zimmer, Lynn. 1988. "Tokenism and Women in the Workplace: The Limits of Gender-Neutral Theory." Social Problems 35(1):64-77.

\section{Citation}

Gouliquer, Lynne, Carmen Poulin, and Jennifer McWilliams. 2020. “Othering of Full-Time and Volunteer Women Firefighters in the Canadian Fire Services." Qualitative Sociology Review 16(3):48-69. Retrieved Month, Year (http://www.qualitativesociologyreview.org/ENG/archive_eng.php). DOI: http://dx.doi.org/10.18778/1733-8077.16.3.04 